\title{
Tripartite motif-containing 29 as a novel biomarker in non-small cell lung cancer
}

\author{
XIAOMING SONG ${ }^{1}$, CHUNHAI FU $^{2}$, XUDONG YANG ${ }^{1}$, \\ DONGFENG SUN ${ }^{1}$, XIANQI ZHANG ${ }^{1}$ and JIANDONG ZHANG $^{1}$ \\ ${ }^{1}$ Department of Thoracic Surgery, Shandong Qianfoshan Hospital, Jinan, Shandong 250014; \\ ${ }^{2}$ Department of Thoracic Surgery, Hospital of Shandong Aluminum Corporation, Zibo, Shandong 255069, P.R. China
}

Received September 7, 2014; Accepted June 2, 2015

DOI: $10.3892 / \mathrm{ol} .2015 .3623$

\begin{abstract}
Tripartite motif-containing 29 (TRIM29) is a member of the tripartite motif (TRIM) protein family. TRIM29 has been reported to be deregulated in a number of cancer types, suggesting the oncogenic function of TRIM29. However, its clinical significance in non-small cell lung cancer (NSCLC) has not been fully elucidated. In the present study, the TRIM29 expression status was investigated by immunohistochemical analysis in paraffin-embedded specimens obtained from 320 patients with surgically resected NSCLC, treated between 2000 and 2007. High TRIM29 expression was significantly associated with smoking $(\mathrm{P}=0.012)$, T stage $(\mathrm{P}=0.015)$ and $\mathrm{M}$ stage $(\mathrm{P}=0.003)$. Furthermore, elevated TRIM29 expression level was correlated with reduced overall (OS) and disease-free survival. In addition, high TRIM29 expression was an independent prognostic factor for $\mathrm{OS}[\mathrm{P}=0.003$, hazard ratio $(\mathrm{HR})=2.102,95 \%$ confidence interval (CI), 1.069-3.193]. In conclusion, these results suggest that TRIM29 may be a useful prognostic marker in NSCLC patients and a potential molecular target for NSCLC treatment.
\end{abstract}

\section{Introduction}

Non-small cell lung cancer (NSCLC) accounts for $\sim 80 \%$ of all lung cancer cases (1) and is the most common cause of cancer-associated mortality worldwide (2). Globally, the annual diagnosis rate of new NSCLC cases is $~ 1.6$ million, with the rate increasing over the last decades (3). A previous study demonstrated the importance of molecular characterization of these tumors and the identification of potential molecular targets for treatment (3). However, the prognosis

Correspondence to: Dr Jiandong Zhang, Department of Thoracic Surgery, Shandong Qianfoshan Hospital, 16,766 Jingshi Road, Jinan, Shandong 250014, P.R. China

E-mail: jiandong_zhang@yeah.net

Key words: TRIM29, non-small cell lung cancer, prognosis, biomarker in these patients remains poor as the overall 5-year survival is $<15 \%$ (4). These unsatisfactory clinical outcomes indicate the requirement for more reliable predictors of survival and novel therapeutic targets (3).

The tripartite motif (TRIM) family members are involved in numerous biological processes and, when altered, are implicated in a number of pathological conditions (5). TRIM29, which is also known as ataxia-telangiectasia group D complementing protein (ATDC), is a member of the TRIM family proteins (6). TRIM29 is highly expressed in gastric cancer and is involved in the differentiation, proliferation and progression of gastric cancer cells (7). In addition, TRIM29 was found to be overexpressed in bladder cancer, ovarian serous papillary tumors and endometrial neoplasms $(8,9)$. However, the clinical significance and prognostic value of TRIM29 expression in NSCLC patients remain unclear. The present study aimed to investigate the association between TRIM29 expression and the clinicopathological features of NSCLC, as well as examine the potential role of TRIM29 as a prognostic factor in NSCLC patients.

\section{Materials and methods}

Patients and histological evaluation. NSCLC patients who were diagnosed, treated and followed-up at the Department of Thoracic Surgery (Shandong Qianfoshan Hospital, Jinan, China) between January 2000 and January 2007 were recruited in this study. The inclusion criteria were as follows: Patients with surgically resected and pathologically confirmed primary NSCLC, complete medical records and available paraffin-embedded specimens were included. In total, 320 patients with NSCLC were enrolled, including 221 patients treated with lobectomy and 99 patients treated with pneumonectomy. Clinical variables were retrieved from the patients' medical records, including age, gender, and survival or disease progression (Table I). Tumor diagnosis and histological classification were based on a new multidisciplinary classification of lung cancer proposed by the International Association for the Study of Lung Cancer, American Thoracic Society, and European Respiratory Society (10). Tumors were staged according to the 7th edition of the TNM Classification of Malignant Tumors $(11,12)$. Normal bronchial epithelium obtained from noncancerous 
Table I. Association between TRIM29 expression and clinicopathological features.

\begin{tabular}{|c|c|c|c|}
\hline \multirow[b]{2}{*}{ Characteristic } & \multicolumn{2}{|c|}{ TRIM29 expression } & \multirow[b]{2}{*}{ P-value } \\
\hline & High & Low & \\
\hline Patients, n (\%) & $79(24.7)$ & $241(75.3)$ & \\
\hline Gender, n (\%) & & & 0.092 \\
\hline Male & $65(82.3)$ & $214(88.8)$ & \\
\hline Female & $14(17.7)$ & $27(11.2)$ & \\
\hline Mean age $\pm S D$, years & $57.32 \pm 11.8$ & $59.26 \pm 9.77$ & 0.113 \\
\hline Smoking status, n (\%) & & & 0.012 \\
\hline Smoker & $50(63.3)$ & $200(83)$ & \\
\hline Non-smoker & $29(36.7)$ & $41(17)$ & \\
\hline Histology, n (\%) & & & 0.821 \\
\hline $\mathrm{SCC}$ & $31(39.2)$ & $184(76.3)$ & \\
\hline $\mathrm{ADC}$ & $48(60.8)$ & $57(23.7)$ & \\
\hline Pathological stage, n (\%) & & & 0.210 \\
\hline Stage I & $28(35.4)$ & $110(45.6)$ & \\
\hline Stage II & $26(32.9)$ & $72(29.9)$ & \\
\hline Stage III & $21(26.6)$ & $50(20.7)$ & \\
\hline Stage IV & $4(5.1)$ & $9(3.7)$ & \\
\hline T stage, n (\%) & & & 0.015 \\
\hline $\mathrm{T} 1$ & $23(29.1)$ & $30(12.4)$ & \\
\hline $\mathrm{T} 2$ & $40(50.6)$ & $163(67.6)$ & \\
\hline $\mathrm{T} 3$ & $12(15.2)$ & $20(8.3)$ & \\
\hline $\mathrm{T} 4$ & $4(5.1)$ & $28(11.7)$ & \\
\hline N stage, n (\%) & & & 0.920 \\
\hline No & $48(60.8)$ & $147(61)$ & \\
\hline N1 & 15 (19) & $51(21.2)$ & \\
\hline $\mathrm{N} 2$ & $16(20.2)$ & $43(17.8)$ & \\
\hline M stage, n (\%) & & & 0.003 \\
\hline M0 & $29(36.7)$ & $205(85.1)$ & \\
\hline M1 & $50(63.3)$ & $36(14.9)$ & \\
\hline
\end{tabular}

TRIM29, tripartite motif-containing 29; SD, standard deviation; SCC, squamous cell carcinoma; ADC, adenocarcinoma; T stage, tumor size; $\mathrm{N}$ stage, lymph nodes; M stage, distant metastases.

lung tissue of the NSCLC patients was used as the control. The study was approved by the Institutional Review Board at the Shandong Qianfoshan Hospital. Written informed consent was obtained from all patients.

Follow-up. Standardized follow-up was conducted every 3 months for the first 2 years after surgery, every 6 months for the 3rd year and yearly thereafter. Follow-up included physical examination, complete blood count, chest computed tomography scans, brain magnetic resonance imaging scans and abdominal ultrasound. The median follow-up period for surviving patients was 31.5 months (6-72 months). Disease-free survival (DFS) was defined as the time from the initial surgery until a documented relapse, including locoregional recurrence and distant metastasis. The overall survival (OS) was defined from the date of the initial surgery until mortality or the end of follow-up.
Immunohistochemical analysis. Tissue sections $(6 \mu \mathrm{m})$ were deparaffinized in xylene, rehydrated and heated at $100^{\circ} \mathrm{C}$ in citrate buffer $(\mathrm{pH} 6.0$ ) for $5 \mathrm{~min}$ for nonenzymatic antigen retrieval. The sections were then incubated with monoclonal mouse anti-human TRIM29 antibody (cat. no. H00023650-B01; dilution, 1:100; Novus Biologicals, LLC, Littleton, CO, USA) for $60 \mathrm{~min}$ at room temperature, followed by incubation with a goat anti-mouse immunoglobulin G antibody (cat. no. AI-9200; dilution, 1:1,000; Vector Laboratories, Inc., Burlingame, CA, USA) for $1 \mathrm{~h}$ at room temperature. Staining was performed with 3,3'-diaminobenzidine chromogen for $5 \mathrm{~min}$, followed by counterstaining using hematoxylin (Beijing Solarbio Science \& Technology Co., Ltd., Beijing, China) for $5 \mathrm{~min}$, as previously described (13). Rabbit IgG (cat. no. NP-001; Epitomics Inc., Burlingame, CA, USA) was used as a negative control. TRIM29 expression was scored as follows: 0, no staining; 
Table II. Univariate analyses of overall survival and disease-free survival in 320 patients with non-small cell lung cancer.

\begin{tabular}{|c|c|c|c|c|}
\hline & Overall survival & & Disease-free survival & \\
\hline Characteristic & Hazard ratio $(95 \% \mathrm{CI})$ & P-value & Hazard ratio $(95 \% \mathrm{CI})$ & P-value \\
\hline TRIM29 expression & & 0.007 & & 0.014 \\
\hline Low vs. high & $1.52(1.120-2.061)$ & & $1.51(1.089-2.119)$ & \\
\hline Gender & & 0.134 & & 0.982 \\
\hline Female vs. male & $0.56(0.267-1.049)$ & & $0.97(0.670-1.427)$ & \\
\hline Smoking status & & 0.025 & & 0.190 \\
\hline No vs. yes & $1.48(1.049-2.138)$ & & $0.80(0.570-1.121)$ & \\
\hline Age, years & & 0.079 & & 0.447 \\
\hline$\leq 60$ vs. $>60$ & $1.43(1.036-1.901)$ & & $0.82(0.642-1.213)$ & \\
\hline Histology & & 0.814 & & 0.625 \\
\hline SCC vs. ADC & $1.07(0.766-1.403)$ & & $1.34(0.979-1.858)$ & \\
\hline Stage & & $<0.001$ & & $<0.001$ \\
\hline I/II vs. III/IV & $2.69(1.933-3.550)$ & & $1.86(1.314-2.648)$ & \\
\hline T stage & & $<0.001$ & & $<0.001$ \\
\hline T1/T2 vs. T3/T4 & $2.84(2.082-3.995)$ & & $2.35(1.621-3.429)$ & \\
\hline $\mathrm{N}$ stage & & $<0.001$ & & $<0.001$ \\
\hline N0 vs. N1/N2 & $2.30(1.725-3.120)$ & & $1.96(1.419-2.695)$ & \\
\hline M stage & & $<0.001$ & & $<0.001$ \\
\hline M0 vs. M1 & $2.54(1.894-3.725)$ & & $2.02(1.711-3.502)$ & \\
\hline
\end{tabular}

CI, confidence interval; SCC, squamous cell carcinoma; ADC, adenocarcinoma; T stage, tumor size; N stage, lymph nodes; M stage, distant metastases.
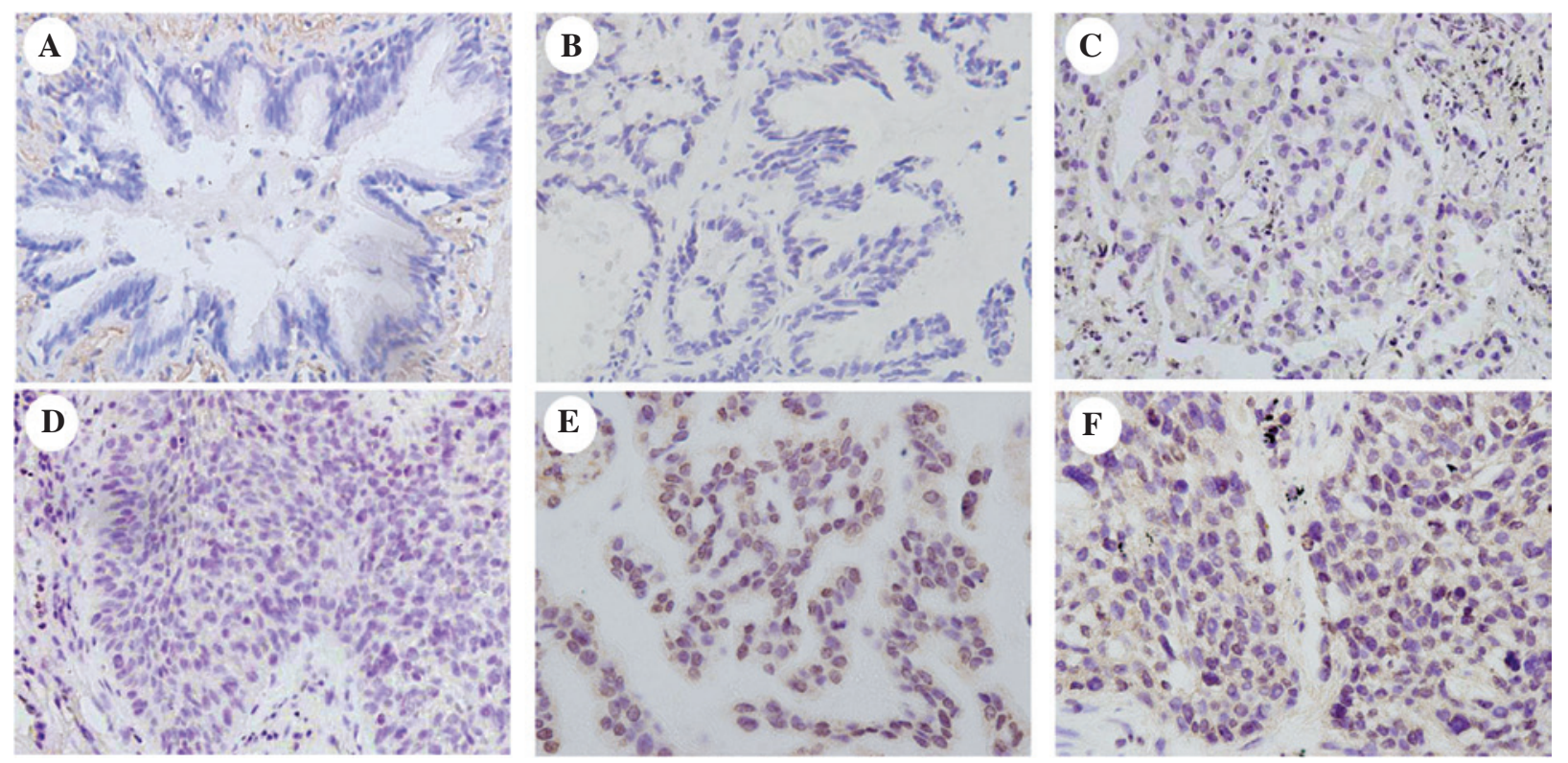

Figure 1. Immunohistochemical staining of TRIM29 in lung cancer tissue specimens. (A) Negative staining in normal bronchial epithelium of noncancerous lung tissue (control). (B) Negative control using rabbit immunoglobulin. (C) Weak TRIM29 staining in lung adenocarcinoma. (D) Weak TRIM29 staining in a case of squamous cell carcinoma. (E) Positive TRIM29 staining in a case of lung adenocarcinoma. (F) Positive TRIM29 staining in a case of squamous cell carcinoma. TRIM29, tripartite motif-containing 29.

$1+,<10 \%$ of tumor cells expressing TRIM29; $2+, 10-50 \%$ of tumor cells expressing TRIM29; and $3+,>50 \%$ of tumor cells expressing TRIM29. Scores of 0 and 1+ were classified as low TRIM29 expression, whereas scores of $2+$ and $3+$ were classified as high TRIM29 expression. The scoring is a modification of a previously described classification (14). Two 
Table III. Multivariate analyses of overall survival and disease-free survival in 320 patients with non-small cell lung cancer.

\begin{tabular}{|c|c|c|c|c|}
\hline & Overall survival & & Disease-free survival & \\
\hline Characteristic & Hazard ratio $(95 \% \mathrm{CI})$ & P-value & Hazard ratio $(95 \% \mathrm{CI})$ & P-value \\
\hline TRIM29 expression & & 0.003 & & 0.064 \\
\hline Low vs. high & $2.102(1.069-3.193)$ & & $1.384(0.982-1.952)$ & \\
\hline Gender & & 0.036 & & 0.331 \\
\hline Female vs. male & $1.921(1.044-3.535)$ & & $1.327(0.750-2.347)$ & \\
\hline Smoking status & & 0.312 & & 0.406 \\
\hline No vs. yes & $1.277(0.795-2.052)$ & & $0.813(0.499-1.325)$ & \\
\hline Age, years & & 0.001 & & 0.692 \\
\hline$\leq 60$ vs. $>60$ & $1.752(1.274-2.410)$ & & $1.070(0.766-1.495)$ & \\
\hline Histology & & 0.007 & & 0.040 \\
\hline SCC vs. ADC & $1.611(1.141-2.275)$ & & $1.506(1.020-2.225)$ & \\
\hline Stage & & 0.415 & & 0.649 \\
\hline I/II vs. III/IV & $1.196(0.778-1.838)$ & & $0.891(0.543-1.463)$ & \\
\hline T stage & & $<0.001$ & & $<0.001$ \\
\hline T1/T2 vs. T3/T4 & $2.050(1.371-3.065)$ & & $2.246(1.427-3.537)$ & \\
\hline $\mathrm{N}$ stage & & $<0.001$ & & $<0.001$ \\
\hline N0 vs. N1/N2 & $2.053(1.592-3.413)$ & & $1.817(1.100-2.713)$ & \\
\hline M stage & & $<0.001$ & & 0.001 \\
\hline M0 vs. M1 & $2.316(1.618-3.313)$ & & $1.952(1.320-2.888)$ & \\
\hline
\end{tabular}

CI, confidence interval; SCC, squamous cell carcinoma; ADC, adenocarcinoma; T stage, tumor size; N stage, lymph nodes; M stage, distant metastases.
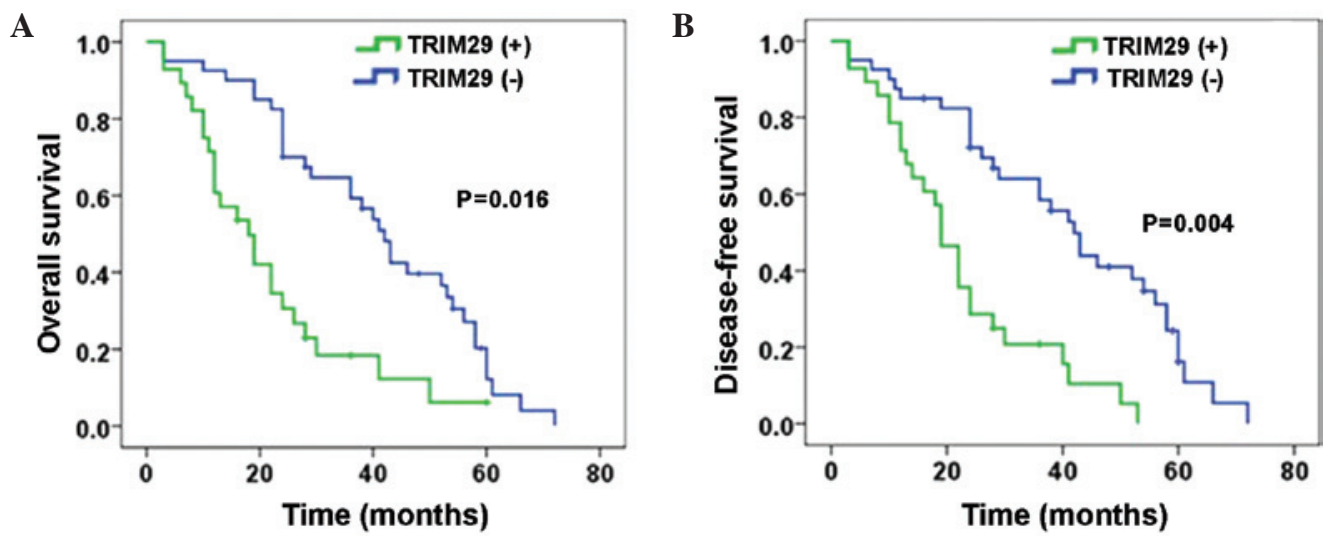

Figure 2. Kaplan-Meier curves for (A) overall survival and (B) disease-free survival in all non-small-cell lung cancer patients. TRIM29, tripartite motif-containing 29; (+), positive expression; (-), negative expression.

pathologists blinded to the patients' clinical data interpreted all the slides and agreed on the classification of the sections into the low or high TRIM29 expression groups.

Statistical analysis. In order to determine any possible associations between qualitative clinicopathological variables and TRIM29 expression, the $\chi^{2}$ test or two-tailed Fisher's exact test was applied. Survival differences among the high- and low-expression groups were calculated using the Kaplan-Meier method along with the log-rank test. The Cox proportional hazards model was used for multivariate analyses of OS and DFS. SPSS version 16.0 statistical software (SPSS Inc., Chicago, IL, USA) was used for all statistical analyses. $\mathrm{P}<0.05$ was considered to indicate a statistically significant difference.

\section{Results}

Association between TRIM29 expression and clinicopathological features of NSCLC patients. Various patient characteristics and their correlation with TRIM29 expression are listed in Table I. The mean age at diagnosis was 
$58.9 \pm 10.7$ years (range, $34-82$ years). A total of 138 patients (43.1\%) were diagnosed with stage I, 98 (30.6\%) with stage II, $71(22.2 \%)$ with stage III and $13(4.1 \%)$ with stage IV disease. TRIM29 expression was predominantly localized in the nuclear compartments of the tumor cells, while the normal bronchial epithelia exhibited negative or low staining (Fig. 1).

The association between total TRIM29 expression and various clinical parameters was investigated. As shown in Table I, a high TRIM29 expression was significantly associated with smoking $(\mathrm{P}=0.012)$, a higher T stage $(\mathrm{P}=0.015)$ and a higher $\mathrm{M}$ stage $(\mathrm{P}=0.003)$. However, no statistically significant correlation was observed between TRIM29 expression and other clinical features.

Association between TRIM29 expression and OS or DFS. The prognostic relevance of TRIM29 expression and other clinicopathological parameters with regard to OS and DFS in patients with NSCLC was investigated (Table II; Fig. 2A and B). Patients with high TRIM29 expression presented shorter OS and DFS rates compared with patients with low TRIM29 expression $(\mathrm{P}=0.007$ and $\mathrm{P}=0.014$, respectively). In addition, pathological stage (I/II vs. III/IV) and TNM stage were demonstrated to be independent prognostic factors affecting OS and DFS ( $\mathrm{P}<0.001$; Table II). Furhtermore, high TRIM29 expression was demonstrated to be an independent prognostic factor affecting $\mathrm{OS}(\mathrm{P}=0.003$; hazard ratio, 2.102; 95\% confidence interval, 1.069-3.193) using multivariate analyses (Table III).

\section{Discussion}

The aim of the present study was to determine the prognostic significance of TRIM29 protein expression in NSCLC. Based on the findings of the current study, TRIM29 overexpression appears to be associated with aggressive tumor behavior and ultimately influences patients' clinical outcomes. In addition, a high TRIM29 expression was prevalent in smokers and was found to be an unfavorable clinical factor in NSCLC.

Recent evidence has suggested that TRIM29 promotes cancer cell proliferation via inhibiting the nuclear activities of p53, which is a major tumor suppressor gene involved in the determination of proliferation or growth arrest at the cellular level $(15,16)$. TRIM29 binds $\mathrm{p} 53$ and represses the expression of p53-regulated genes, including $p 21$ and NOXA $(15,17)$. In addition, TRIM29 is selectively expressed in basal cells of the normal prostate gland. In a previous study, immunohistochemical staining with anti-TRIM29 antibody revealed the same expression pattern as that observed for staining with $34 \beta E 12$ in prostate cancer and its benign mimics, indicating that TRIM29 may be useful for distinguishing prostate cancer from benign tissues (18). Furthermore, younger females with early-stage breast cancer who were not administered adjuvant systemic therapy had a significantly lower risk of relapse when their tumor exhibited a high TRIM29 expression (19). This finding suggests that loss of TRIM29 expression in normal breast luminal cells can contribute to malignant transformation and lead to progression of breast cancer in premenopausal women (19). The expression of TRIM29 was also significantly associated with progression to muscle-invasive bladder cancer and was identified as an independent prognostic marker (20). In addition, TRIM29 has been reported to upregulate matrix metalloproteinase 9 to promote lung cancer cell invasion by activating the extracellular signal-regulated kinase and c-Jun N-terminal kinase signaling pathways (21). Previous results have identified a DNA repair pathway leading from MAPK-activated protein kinase-2 and ataxia telangiectasia mutated to TRIM29 (22). Therefore, as TRIM29 has been used as a therapeutic target to radiosensitize pancreatic ductal adenocarcinoma and improve the efficacy of DNA-damaging treatment in pancreatic cancer (22), the use of TRIM29 as a potential therapeutic target for the treatment of NSCLC was investigated in the present study.

In conclusion, in the present study, TRIM29 expression was investigated by immunohistochemical analysis in paraffin-embedded specimens obtained from 320 patients with surgically resected NSCLC, treated between 2000 and 2007. High TRIM29 expression was significantly associated with smoking, T stage and $\mathrm{M}$ stage. Furthermore, elevated TRIM29 expression level was correlated with reduced OS and DFS and was an independent prognostic factor for OS in NSCLC. Therefore, TRIM29 may be a useful prognostic marker in NSCLC patients and a potential molecular target for NSCLC treatment.

\section{References}

1. Dempke WC, Suto T and Reck M: Targeted therapies for non-small cell lung cancer. Lung Cancer 67: 257-274, 2010.

2. Greenlee RT, Hill-Harmon MB, Murray T and Thun M: Cancer statistics. CA Cancer J Clin 51: 15-36, 2011.

3. Gainor JF and Shaw AT: Novel targets in non-small cell lung cancer: ROS1 and RET fusions. Oncologist 18: 865-875, 2013.

4. Villarreal-Garza C, de la Mata D, Zavala DG, Macedo-Perez EO and Arrieta O: Aggressive treatment of primary tumor in patients with non-small-cell lung cancer and exclusively brain metastases. Clin Lung Cancer 14: 6-13, 2013.

5. Napolitano LM and Meroni G: TRIM family: Pleiotropy and diversification through homomultimer and heteromultimer formation. IUBMB Life 64: 64-71, 2012.

6. Hatakeyama S: TRIM proteins and cancer. Nat Rev Cancer 11: 792-804, 2011.

7. Kosaka Y, Inoue H, Ohmachi T, Yokoe T, Matsumoto T, Mimori K, Tanaka F, Watanabe M and Mori M: Tripartite motif-containing 29 (TRIM29) is a novel marker for lymph node metastasis in gastric cancer. Ann Surg Oncol 14: 2543-2549, 2007.

8. Santin AD, Zhan F, Bellone S, Palmieri M, Cane S, Bignotti E, Anfossi S, Gokden M, Dunn D, Roman JJ, et al: Gene expression profiles in primary ovarian serous papillary tumors and normal ovarian epithelium: Identification of candidate molecular markers for ovarian cancer diagnosis and therapy. Int J Cancer 112: 14-25, 2004.

9. Dyrskjøt L, Kruhøffer M, Thykjaer T, Marcussen N, Jensen JL, Møller K and Ørntoft TF: Gene expression in the urinary bladder: A common carcinoma in situ gene expression signature exists disregarding histopathological classification. Cancer Res 64: 4040-4048, 2004.

10. Travis WD, Brambilla E, Noguchi M, Nicholson AG, Geisinger KR, Yatabe Y, Beer DG, Powell CA, Riely GJ, Van Schil PE, et al: International association for the study of lung cancer/american thoracic society/european respiratory society international multidisciplinary classification of lung adenocarcinoma. J Thorac Oncol 6: 244-285, 2011.

11. Goldstraw P, Crowley J, Chansky K, et al; International Association for the Study of Lung Cancer International Staging Committee; Participating Institutions: The IASLC Lung Cancer Staging Project: Proposals for the revision of the TNM stage groupings in the forthcoming (seventh) edition of the TNM Classification of malignant tumours. J Thorac Oncol 2: 706-714, 2007 
12. Groome PA, Bolejack V, Crowley JJ, et al: The IASLC Lung Cancer Staging Project: Validation of the proposals for revision of the $\mathrm{T}, \mathrm{N}$, and $\mathrm{M}$ descriptors and consequent stage groupings in the forthcoming (seventh) edition of the TNM classification of Malignant Tumours. J Thorac Oncol 2: 694-705, 2007.

13. Kwon MJ, Park S, Choi JY, Oh E, Kim YJ, Park YH, Cho EY, Kwon MJ, Nam SJ, Im YH, et al: Clinical significance of CD151 overexpression in subtypes of invasive breast cancer. $\mathrm{Br} \mathrm{J}$ Cancer 106: 923-930, 2012.

14. Suzuki S, Miyazaki T, Tanaka N, Sakai M, Sano A, Inose T, Sohda M, Nakajima M, Kato H and Kuwano H: Prognostic significance of CD151 expression in esophageal squamous cell carcinoma with aggressive cell proliferation and invasiveness. Ann Surg Oncol 18: 888-893, 2011.

15. Yuan Z, Villagra A, Peng L, Coppola D, Glozak M, Sotomayor EM, Chen J, Lane WS and Seto E: The ATDC (TRIM29) protein binds p53 and antagonizes p53-mediated functions. Mol Cell Biol 30: 3004-3015, 2010

16. Sho T, Tsukiyama T, Sato T, Kondo T, Cheng J, Saku T, Asaka M and Hatakeyama S: TRIM29 negatively regulates $\mathrm{p} 53$ via inhibition of Tip60. Biochim Biophys Acta 1813: 1245-1253, 2011.

17. Shibata MA, Yoshidome K, Shibata E, Jorcyk CL and Green JE: Suppression of mammary carcinoma growth in vitro and in vivo by inducible expression of the Cdk inhibitor p21. Cancer Gene Ther 8: $23-35,2001$.
18. Kanno Y, Watanabe M, Kimura T, Nonomura K, Tanaka S and Hatakeyama S: TRIM29 as a novel prostate basal cell marker for diagnosis of prostate cancer. Acta Histochem 116: 708-712, 2014.

19. Liu J, Welm B, Boucher KM, Ebbert MT and Bernard PS: TRIM29 functions as a tumor suppressor in nontumorigenic breast cells and invasive ER+breast cancer. Am J Pathol 180: 839-847, 2012

20. Fristrup N, Birkenkamp-Demtröder K, Reinert T, Sanchez-Carbayo M, Segersten U, Malmström PU, Palou J, Alvarez-Múgica M, Pan CC, Ulhøi BP, et al: Multicenter validation of cyclin D1, MCM7, TRIM29 and UBE2C as prognostic protein markers in non-muscle-invasive bladder cancer. Am J Pathol 182: 339-349, 2013.

21. Tang ZP, Cui QZ, Dong QZ, Xu K and Wang EH: Ataxia-telangiectasia group D complementing gene (ATDC) upregulates matrix metalloproteinase 9 (MMP-9) to promote lung cancer cell invasion by activating ERK and JNK pathways. Tumour Biol 34: 2835-2842, 2013.

22. Wang L, Yang H, Palmbos PL, Ney G, Detzler TA, Coleman D, Leflein J, Davis M, Zhang M, Tang W, et al: ATDC/TRIM29 phosphorylation by ATM/MAPKAP kinase 2 mediates radioresistance in pancreatic cancer cells. Cancer Res 74: 1778-1788, 2014. 